\title{
Obesity and Cardiovascular Risk in the Arab Gulf States
}

\author{
Assim M. AlAbdulKader ${ }^{1,2} \cdot$ Khaled Tuwairqi $^{3,4} \cdot$ Goutham Rao $^{1}$
}

Published online: 20 May 2020

(C) The Author(s) 2020

\begin{abstract}
Purpose of Review Rapid economic growth in the Gulf Cooperation Council (GCC) states over the last half-century has been associated with a rise in obesity and cardiovascular morbidity and mortality. In this review, we shed some light on the factors driving the obesity epidemic, promising interventions to overcome this public health crisis, and challenges precluding a successful public health impact.

Recent Findings Overweight and obesity rates have nearly tripled in the GCC countries over the past four decades. Cardiovascular morbidity and mortality have been rising in parallel. Several sociodemographic, environmental, and behavioral factors have been correlated with sedentary lifestyle and unhealthy diet habits, and ultimately the rise in overweight and obesity rates. Numerous studies have documented factors unique to the population of the Arab Gulf states, but high-quality data is scarce. Despite the growing awareness of the extent of the problem, several barriers to weight loss and physical activity need to be addressed. A few interventions to combat obesity at different levels have been reported with some promising outcomes. Using the social-ecological model (SEM), we review recently published interventions and discuss some challenges to overcome in order to make progress in fighting the obesity epidemic in the GCC.

Summary Obesity prevalence has been mounting worldwide, and the Arab Gulf states are no exception. This public health crisis is drawing the attention of policymakers and several stakeholders. However, a lot needs to be done to reduce the burden of obesity and improve cardiovascular risks in the Arab Gulf states.
\end{abstract}

Keywords Overweight and obesity $\cdot$ Cardiovascular risk and diseases $\cdot$ Lifestyle physical activity $\cdot$ Social-ecological model $(\mathrm{SEM}) \cdot$ Arab gulf states $\cdot$ Gulf Cooperation Council (GCC)

This article is part of the Topical Collection on Obesity and Diet

Assim M. AlAbdulKader

ama211@ case.edu

Khaled Tuwairqi

Khaled.tuwairqi@uhhospitals.org

Goutham Rao

Goutham.Rao@uhhospitals.org

1 Department of Family Medicine and Community Health, Case Western Reserve University, University Hospitals of Cleveland, Lerner Tower 1056, Mailstop BHC 5036, 11100 Euclid Avenue, Cleveland, OH 44106, USA

2 Department of Family and Community Medicine, Imam Abdulrahman bin Faisal University, Dammam, Saudi Arabia

3 Harrington Heart and Vascular Institute, University Hospitals of Cleveland, Case Western Reserve University, Cleveland, OH, USA

4 Department of Cardiology, Heart Center, King Faisal Specialist Hospital and Research Center, Riyadh, Saudi Arabia

\section{Introduction}

Prevalence of overweight (body mass index $[\mathrm{BMI}] \geq 25$ ) and obesity (BMI $\geq 30$ ) have nearly tripled worldwide since 1975 [1]. Obesity trends are particularly alarming in the Arab States of the Gulf Cooperation Council (GCC), which include Bahrain, Kuwait, Oman, Qatar, Saudi Arabia (SA), and United Arab Emirates (UAE). As of 2016, the World Health Organization (WHO) estimated the obesity rates among adults in Kuwait at 37\%, followed by Saudi Arabia (35\%) and Qatar $(34 \%)$. Prevalence is significantly higher in adult females, especially in Kuwait (44\%), Qatar (42\%), and Saudi Arabia (41\%). The trend is also disturbing among adolescents [2], nearly reaching $20 \%$ among males and females ages 10 19 years old. Excess body weight is associated with increased risks of non-communicable disease (NCDs) [3, 4], including cardiovascular diseases (CVDs), hypertension (HTN), hyperlipidemia (HLD), and type 2 diabetes (T2D). CVDs (myocardial infarction and stroke) account for most of the global burden of NCDs and associated premature mortality $[5,6]$. In the 
Arab GCC countries cardiovascular disease accounts for a large share of mortality (Table 1). Most of these deaths are potentially preventable.

A few systematic literature reviews have addressed overweight and obesity in the GCC Arab states [7, 8]. However, reviews that apply the social-ecological model (SEM) in examining obesity-related interventions in the GCC Arab states do not exist. In this qualitative review, we briefly summarize the factors driving the obesity epidemic in the Arab GCC countries based on local and regional studies. These factors include sociodemographic, physical activity and sedentary lifestyle, dietary behavior, and other factors. Furthermore, we use the SEM framework to examine local and regional interventions targeting obesity. This is especially important to consider when designing and implementing successful prevention and reduction programs. Finally, we discuss challenges precluding the implementation of strategies that were successful outside the GCC, taking into consideration environmental, social, and cultural factors.

We searched the PubMed database for peer-reviewed articles published between 2010 and 2019, using the following keywords: "overweight, obesity, cardiovascular risk, cardiovascular disease, intervention, Arab, gulf states, GCC, Bahrain, Kuwait, Oman, Qatar, Saudi Arabia, United Arab Emirates." Additionally, we utilized recent systematic reviews to guide our search for relevant published work. This review aims to inform policymakers, health care professionals, and other stakeholders in the Arab GCC states with potential opportunities to combat the obesity epidemic.

\section{Factors Contributing to Overweight and Obesity in the Arab GCC States}

\section{Overview}

We found numerous studies addressing risk factors related to overweight and obesity, most carried out in Saudi Arabia or Kuwait. In this section, we summarize the key factors related to social and demographic, activity and lifestyle, and dietary behaviors associated with overweight and obesity in the Arab GCC countries.

\section{Social and Demographic Factors}

Over the past half-century, the economic prosperity and urbanization of the Arab GCC countries have brought with it a massive burden of NCDs, including obesity and its associated CVDs. All published studies we found were cross-sectional, making it difficult to infer causality. Overweight and obesity were correlated with increased age [9-11], lower level of education and unemployment. Older people and those who do not work tend to stay at home more often and be less 
physically active. Furthermore, those who are married [10-13] or live in an urban setting were more likely to be overweight or obese. This has been attributed to the social behavior of couples spending more time with each other over meals, and hence eat more and live a sedentary lifestyle. On the other hand, it has been reported that Bedouins who live in isolated rural areas and consume traditional foods have lower rates of obesity compared to those who live an urbanized areas [14]. These findings are mostly similar to other cultures [15].

We found conflicting results about the relationship between sex and BMI. Some studies reported higher BMI among males [16-20], others, and females [11, 21-24]. A few studies suggested that males have higher rates of "overweight," while females have higher "obesity" rates [25-27]. These mixed findings speak to the heterogeneity and limited generalizability of the published observational studies. The WHO statistics found that male children and adolescents have higher rates of obesity, compared with females. Conversely, the prevalence of obesity among female adults is significantly higher than males (Table 1). Although there is no clear explanation for this trend, cultural and environmental factors probably have a significant role. There has been an ancient cultural assumption linking excess body weight to better health and fertility, especially in women. Some experts attribute the gender difference in obesity rates to pregnancy and childbirth, socio-cultural boundaries on women, and the relatively less public role of women, probably leading to a more sedentary lifestyle.

Studies examining environmental factors of obesity are limited. Regional public health and obesity experts have commented on the impact of the environment on obesity rates in the GCC states. For instance, "The desert environment and lifestyle factors have an impact on biology, so you are talking about a gene-environment interaction, as is the case for most chronic diseases," [28] says Dr. Nadia Ahmad, director of Obesity Medicine Institute in Dubai, UAE.

\section{Lifestyle Physical Activity}

It is well-known that physical inactivity and a sedentary lifestyle are linked to weight gain, obesity, and chronic diseases [29]. The prevalence of physical inactivity in the Arab GCC countries is high [30]. Based on the WHO surveys on noncommunicable disease risk factors (STEPS), more than $62 \%$, and $67 \%$ of Kuwaiti and Saudi Arabian adults are physically inactive, respectively. The rates of physical inactivity among children and adolescents are also disturbing with an estimated $72 \%$ in UAE and $85 \%$ in Qatar, based on the WHO Global school-based student health survey (GSHS).

Most studies showed that women tend to be less physically active than men $[25,26,31-34]$. In a large cross-sectional study of a sample of 1830 individuals (20-86 years old) conducted in Kuwait, only $4.7 \%$ of males reported being physically active, compared to $1.3 \%$ of females [26]. A study in Saudi Arabia included 1257 male and female college students showed that females performed more walking activities, while males tend to have more idle leisure time. Moreover, membership in sports clubs was associated with being more active [35].

Age, marital status, parity, educational level, and employment were also correlated to physical activity level. Older individuals ( $>40$ years old) $[32,34,36,37]$ and those who are married $[34,38,39]$ are reportedly less physically active. While some studies reported that higher educational and occupational status in the GCC is associated with less physical activity $[32,39]$, other studies suggest the contrary [35, 40]. Furthermore, work setting and work hours shown to have an impact on physical activity, especially in women. According to a study that included 420 Saudi female workers revealed that those who work seven or more hours a day in the private sector, as opposed to the public sector, and those who do not have children were found to be less physically active [10].

Environmental and cultural barriers to physical activity in the GCC region cannot be underestimated. The harsh weather poses a significant challenge, especially during a scorching summer between April and October, with daytime temperature ranging from 40 to $45^{\circ} \mathrm{C}\left(104-113{ }^{\circ} \mathrm{F}\right)$ in Saudi Arabia. Besides, the built environment is not walk-friendly, which hinder outdoor exercise and promote car use [41]. Culturally, parents tend to prioritize spiritual and educational goals for their children, over sports or physical activities [42]. Inactive social gatherings over food or setting games are the predominant leisure activity [43]. Collectively, these factors discourage physical activity and promote a sedentary lifestyle and ultimately leading to more weight gain and higher obesity rates.

\section{Dietary Behaviors}

The rapid economic growth of the GCC region has given to a rise in trade liberalization and westernization of dietary patterns [44], which are known key contributors to the global obesity epidemic [45]. Studies that looked at obesogenic dietary behaviors (e.g., low intake of fruits and vegetable, overconsumption of fast food and sugary beverages, and unhealthy eating patterns) mostly reported sociodemographic correlates. In the Arab GCC countries, women consume more vegetables [26, 46], while men consume more fruits [33]. However, the overall consumption of fruits and vegetable is well below the recommended amount (five servings per day) [47-51]. Older people and those with higher BMI reported higher intake of fruits and vegetables, while inactive individuals and smokers were less likely to consume fruits and vegetables [50]. Perceived benefits (e.g., weight maintenance and disease prevention) were positively correlated with higher fruits and vegetable consumption [51]. Eating fast food and drinking soft 
drinks were higher among men $[33,52,53]$, while women tend to consume more afternoon snacks and sugarsweetened beverages [52]. One study correlated these behaviors with shift duty work [54]. Unhealthy meal patterns (e.g., irregular or infrequent meals) were commonly reported among college students in Saudi Arabia [48]. Moreover, unhealthy dietary habits (e.g., consumption of fast food and soft drinks) and sedentary lifestyle were common among young women who also reported skipping breakfast [55]. Similar to other parts of the world, and consistent with current scientific knowledge, these dietary behaviors correlate with weight gain and obesity in the Arab GCC countries.

\section{Other Factors}

There is a growing body of evidence relating stress and sleep pattern, via behavioral or metabolic disturbances, to weight gain and obesity [56]. Sleep-deprived individuals tend to crave eating due to enhanced appetite and have less motivation for physical activity [57]. A few observational studies in the GCC reported an association between lack of high-quality sleep and short sleep duration were linked to weight gain and obesity [58-60].

\section{Interventions to Combat the Obesity Epidemic in the Arab GCC States}

\section{Overview}

The SEM, originally described by Bronfenbrenner in 1979 [61], demonstrates distinct yet intersected layers of influence on human behavior. The model consists of five main levels: the individual, interpersonal, organizational, community, and society. It suggests that effective interventions should target multiple levels of influence in order to maximize the impact. This framework has been used by the Nutrition and Physical Activity Program to Prevent Obesity and other chronic diseases (NAPO) at the US Center for Disease Control and Prevention (CDC) to understand and guide programs addressing obesity and chronic diseases [62]. We used the SEM framework to summarize recently published interventions aimed at prevention or control of obesity in the GCC states.

We found that most of the intervention studies were conducted in Saudi Arabia, followed by the United Arab Emirates and Kuwait. Heterogeneity was noted in these studies in terms of the targeted population, age group, intensity, and duration of the intervention. Program evaluation studies had a number of methodological problems including in the study design (e.g., no control group, and small sample size), lack of welldefined intervention strategy (e.g., behavioral and theoretical), follow-up duration (e.g., no follow-up or short interval), and ambiguous or unvalidated outcomes measures. Recent systematic reviews have come to a similar conclusion $[7,8]$. In this section, we shed some light on some successful or promising interventions and call attention to potential future opportunities.

\section{Society and Public Policy Level}

The GCC countries have adopted "The Strategy to Combat Obesity and Promote Physical Activity in Arab Countries," that was proposed during the third Arab Conference on Obesity and Physical Activity in Bahrain in 2010. This strategy guides the governments to prepare their plan of action or strategy to prevent and control obesity. The strategy focuses on nine target areas, including programs for child care centers, schools, primary and secondary health care, food preparation institutes, food companies, public benefit organizations, media, and workplaces [63]. The governments of Arab GCC states, informed by the WHO and the Council for Health Ministers, have adopted "The Gulf plan for prevention and control of NCDs 2014-2025," which directs the health ministries to integrate preventive and curative programs for NCDs, including provisions to address obesity, hypertension, and diabetes. There is a clear understanding among experts that stakeholders and decision-makers need to act and invest in population-based preventive programs (e.g., in schools) to reduce overweight and prevent obesity. "The government has realized that this is a problem, and it has to tackle it right from the beginning and not just treat the complications," [28] says Dr. Faisal Alnasir, professor of Family Medicine at Arabian Gulf University, Bahrain, and advisor to the WHO, Eastern Mediterranean Region (EMRO).

Governments and policymakers have significant power through legislation and regulations. Banning, subsidizing, or taxing of certain goods may be used to influence consumers' behavior. The GCC countries have adopted a unified excise tax on sugar-sweetened beverages. This tax was first implemented by Saudi Arabia in 2017, followed by the UAE, Bahrain, Oman, and Qatar. The prices of soda and energy drinks have increased by $50 \%$ and $100 \%$, respectively. In 2018 , the annual purchases (volume per capita) of soda and energy drinks had decreased by $41 \%$ and $58 \%$, respectively [64]. Additionally, Saudi Arabia has banned soft and energy drinks from being sold in primary and secondary schools.

\section{Community Level}

Population-based interventions in the GCC are limited in number. Most interventions are carried out by government agencies. In Bahrain, the public health wing of the Ministry of Health has been working closely with family physicians in taking a whole-family approach to change lifestyle, such as promoting breastfeeding for babies to reduce their risk of obesity when they grow up. The government has also introduced 
awareness programs designed to change dietary behaviors. In recent years, with the hype of social media, there has been more culturally appropriated content produced and distributed via new media (e.g., YouTube, Instagram, Twitter, and Snapchat), rather than the traditional approach of printed booklets and pamphlets.

In UAE, a population-wide cardiovascular screening program in Abu Dhabi, "Weqaya [prevention]," sought to identify risk factors for CVDs, including overweight, obesity, dyslipidemia, hypertension, and diabetes [65]. In a promising progress, "The UAE Healthy Future" study is seeking to recruit a total of 20,000 UAE nationals to expand further the efforts of identifying risk factors among Emirati adults in order to inform further interventions [66].

\section{Organizational Level}

At this level, organizations, such as health care centers and educational institutes, participate in addressing the obesity crisis by reinforcing healthy behaviors or assisting in maintaining positive lifestyle changes. An educational program was conducted in Qatar, named "Sahtak Awalan - Your Health First." This program targeted 335 elementary school students, where they received teaching about healthy food selection and provided with staff-guided advice. The school cafeteria menu selections were also modified. Students were encouraged to use an accelerometer to monitor their physical activity. While there was a decrease in the frequency of self-reported consumption of rice after the intervention, there was no significant change in other behaviors, including vegetable and unhealthy food intake, and no change in the BMI of the prevalence of obesity after the intervention [67].

A similar but a larger scale intervention is proposed to take place in Saudi Arabia named "Rashaka [fitness]" initiative in collaboration with both ministries of education and health. The initiative plans to include 1000 schools across the country and aims to improve dietary behavior, increase physical activity, and raise awareness of obesity risk [68]. We are not aware of any publications of the outcomes related to this initiative.

Within the health care community, a multidisciplinary panel of regional and international experts developed consensus recommendations for the management of patients with overweight and obesity relevant to the GCC population. The recommendations are based on current international guidelines [69].

\section{Interpersonal Level}

Misconceptions about obesity, its health-related implications, and effective therapies are common in the GCC. A college student survey was done in Saudi Arabia to understand the impact of an obesity educational website measuring healthy decision-making; $32.5 \%$ of the participants expressed that in addition to the Internet, they obtain the health-related information from their family and friends. Nevertheless, only $21 \%$ found no contradiction between the information that was provided between the promoted website and other resources [19]. An example of these misconceptions was reported in a group interview study in Qatar, where some participants report, "some parents think exercise is a shame" [70]. Furthermore, a focus group study in Saudi Arabia unveiled that the lack of social support perceived as a barrier to physical activity and the impact of family and social demands appears to affect females more than males [18].

With the advent of social media and the Internet, researchers from King Saud University in Riyadh have developed a mobile application, "Twazon [balance]," to help with weight loss. The application integrated nutritional facts customized to local Saudi food with motivational components to achieve personalized goals. The end users can share experiences and achievements, including posting photos with each milestone. Despite the extensive work in planning, developing, and implementing the application over nearly 2 years, $80 \%$ of the 240 enrolled participants dropped out during the 4-month study duration. About $65 \%$ of the 40 participants who were engaged with the application lost $2 \%$ of their body weight at 4 months [71].

\section{Individual Level}

A few randomized trials have compared the dietary interventions and their impact on weight loss in the GCC countries. In Saudi Arabia, a trial that focused on intensive lifestyle intervention based on the USPSTF guidelines was conducted through 8 clinic visits and found to be superior to a single clinic visit in achieving $>5 \%$ body weight loss at a 12 -week follow-up [72]. Another randomized trial in Kuwait targeted behavioral modification using the volitional help sheet to form the implementation intention. It showed that this strategy was effective in achieving significant weight loss at 6 months follow-up. Notably, the use of this intervention was conducted in the setting of a commercial weight loss program. There were also missing data related to the subjects' demographics [73]. Nevertheless, this finding was consistent with the previously published studies that have examined the use of volitional help sheet in the west [74]. Remaining lifestyle-related studies published since 2010 in the region were not randomized, including the published data from the comprehensive LIFE-8 program at UAE.

Surgical interventions in the GCC countries have not been studied in a randomized controlled trial. Nevertheless, bariatric surgeries have proven to have the most significant impact on weight loss on an individual level with excess weight loss exceeding $60 \%$ at 1 year follow-up [75]. The international federation for the surgery of obesity and metabolic disorders (IFSO) registry latest report in 2019 , the total registered cases 
from the participating GCC states, were 23,039 cases. Sleeve gastrectomy was by far the most common approach exceeding $80 \%$ of all surgical interventions. Saudi Arabia was found to be the country with the youngest patients at the time of surgery with a median age of 30 years [76]. The IFSO report had no mortality rate data; however, from the first report of the first Kuwait bariatric surgery registry that was published in 2019, there was no in-hospital mortality following the intervention [77]. Other complications following the intervention could range from procedure-related, metabolic, hormonal disturbances, and malabsorption [78].

\section{Challenges and Barriers in Fighting Obesity in the Arab GCC States}

While there were numerous cross-sectional studies conducted in the GCC states that helped explain some of the risk factors associated with obesity, methodological heterogeneity, and conflicting results were common. Hence, evaluating these studies and drawing sound conclusions is challenging. This stresses the importance of well-designed cohort studies that aim to establish causality with reasonable certainty and inform future obesity preventive programs.

At the individual level, behavioral and lifestyle interventions did show a positive impact on weight loss. Nevertheless, the change was modest in some studies, and sufficient followup to assess maintenance of weight loss and long-term clinical outcomes is lacking. On the other hand, weight loss surgery is showing remarkable results. However, there is a need for national registries to monitor long-term outcomes.

The lack of social support and community misconceptions around weight and obesity represent additional barriers. The utilization of social media platforms to spread health information and encourage a healthy lifestyle is one of the promising solutions. Further efforts are needed to ensure the reliability of the content and sustainability of organized mass media campaigns.

When it comes tointerventions at the public policy scale, taxation appears to have the most robust and direct impact on behavior change. School-based interventions, while important, had not shown to have a significant impact on weight loss in Qatar. It is essential, however, to evaluate the implemented program and understand the reasons behind its results. This also raises the demand for standardized intervention strategies and validated evaluation approaches so that the rest of the GCC states can learn from each other's experiences.

\section{Conclusions}

The economic prosperity in the Arab GCC states over the past four decades came with a high price tag. The overweight and obesity rates in the GCC region are one of the highest in the world. Obesity is a complex medical and public health problem. Comprehensive and high-quality studies addressing factors associated with obesity in the GCC region are lacking. Based on the published work reviewed, most of the risk factors leading to obesity and its associated cardiovascular diseases are mostly similar to the rest of the world. Nonetheless, unique sociodemographic and environmental factors deserve special attention. While some successful strategies to prevent and control obesity have been reported worldwide, interventions in the Arab GCC countries are limited. The burden of NCDs is snowballing. Despite the growing awareness among the decision-makers in the GCC region about the economic and health impacts of obesity and cardiovascular diseases, there is a long way ahead to tackle this public health and national security crisis. Standardized methods are needed to better understand the sociodemographic and behavioral contributors to overweight and obesity, especially among children and adolescents. There is an urgent need for intersectoral, multifaceted, and culturally tailored intervention strategies. Finally, robust program evaluation methods should be applied to ensure that interventions are effective and sustainable, and to highlight areas for improvement.

\section{Compliance with Ethical Standards}

Conflict of Interest Assim M AlAbdulKader, Khaled Tuwairqi, Goutham Rao declared no potential conflicts of interest with respect to the research, authorship, and/or publication of this article.

Human and Animal Rights and Informed Consent This article does not contain any studies with human or animal subjects performed by any of the authors.

Open Access This article is licensed under a Creative Commons Attribution 4.0 International License, which permits use, sharing, adaptation, distribution and reproduction in any medium or format, as long as you give appropriate credit to the original author(s) and the source, provide a link to the Creative Commons licence, and indicate if changes were made. The images or other third party material in this article are included in the article's Creative Commons licence, unless indicated otherwise in a credit line to the material. If material is not included in the article's Creative Commons licence and your intended use is not permitted by statutory regulation or exceeds the permitted use, you will need to obtain permission directly from the copyright holder. To view a copy of this licence, visit http://creativecommons.org/licenses/by/4.0/.

\section{References}

1. WHO. Obesity and overweight. https://www.who.int/news-room/ fact-sheets/detail/obesity-and-overweight. Published 2016. Accessed December 10, 2018.

2. Al Hammadi H, Reilly J. Prevalence of obesity among school-age children and adolescents in the Gulf cooperation council (GCC) states: a systematic review. BMC Obes. 2019;6:3. https://doi.org/ 10.1186/s40608-018-0221-5. 
3. Paul P, Giles TD, Bray GA, et al. Obesity and cardiovascular disease: pathophysiology, evaluation, and effect of weight loss. Circulation. 2006;113(6):898-918. https://doi.org/10.1161/ CIRCULATIONAHA.106.171016.

4. Guh DP, Zhang W, Bansback N, Amarsi Z, Birmingham CL, Anis $\mathrm{AH}$. The incidence of co-morbidities related to obesity and overweight: a systematic review and meta-analysis. BMC Public Health. 2009;9(1):88. https://doi.org/10.1186/1471-2458-9-88.

5. Salim Y, Srinath R, Stephanie Ô, Sonia A. Global burden of cardiovascular diseases. Circulation. 2001;104(22):2746-53. https:// doi.org/10.1161/hc4601.099487.

6. Allen L, Cobiac L, Townsend N. Quantifying the global distribution of premature mortality from non-communicable diseases. $\mathrm{J}$ Public Health. 2017;39(4):698-703. https://doi.org/10.1093/ pubmed/fdx008.

7. Al Yazeedi B, Berry DC. Childhood overweight and obesity is increasing in Gulf Cooperation Council countries: a review of the literature. J Transcult Nurs. 2019;1043659619829528. https://doi. org/10.1177/1043659619829528.

8. Balhareth A, Meertens R, Kremers S, Sleddens E. Overweight and obesity among adults in the Gulf States: a systematic literature review of correlates of weight, weight-related behaviours, and interventions. Obes Rev. 2019;20(5):763-93. https://doi.org/10. 1111/obr.12826.

9. Bin Horaib G, Al-Khashan HI, Mishriky AM, et al. Prevalence of obesity among military personnel in Saudi Arabia and associated risk factors. Saudi Med J. 2013;34(4):401-7.

10. Albawardi NM, Jradi H, Al-Hazzaa HM. Levels and correlates of physical activity, inactivity and body mass index among Saudi women working in office jobs in Riyadh city. BMC Womens Health. 2016;16:33. https://doi.org/10.1186/s12905-016-0312-8.

11. Badr HE, Shah NM, Shah MA. Obesity among Kuwaitis aged 50 years or older: prevalence, correlates, and comorbidities. The Gerontologist. 2013;53(4):555-66. https://doi.org/10.1093/geront/ gns 108.

12. Al Qauhiz NM. Obesity among Saudi Female University students: dietary habits and health behaviors. J Egypt Public Health Assoc. 2010;85(1-2):45-59.

13. Khalaf A, Westergren A, Berggren V, Ekblom Ö, Al-Hazzaa HM. Prevalence and association of female weight status and dietary habits with sociodemographic factors: a cross-sectional study in Saudi Arabia. Public Health Nutr. 2015;18(5):784-96. https://doi. org/10.1017/S1368980014001797.

14. Malik M, Bakir A. Prevalence of overweight and obesity among children in the United Arab Emirates. Obes Rev. 2007;8(1):15-20. https://doi.org/10.1111/j.1467-789X.2006.00290.x.

15. Manios Y, Androutsos O, Katsarou C, et al. Prevalence and sociodemographic correlates of overweight and obesity in a large Pan-European cohort of preschool children and their families: the ToyBox study. Nutrer. 2018;55-56:192-8. https://doi.org/10.1016/ j.nut.2018.05.007.

16. Allam AR, Taha IM, Al-Nozha OM, Sultan IE. Nutritional and health status of medical students at a university in Northwestern Saudi Arabia. Saudi Med J. 2012;33(12):1296-303.

17. Abdel-Megeid FY, Abdelkarem HM, El-Fetouh AM. Unhealthy nutritional habits in university students are a risk factor for cardiovascular diseases. Saudi Med J. 2011;32(6):621-7.

18. Al-Otaibi HH. Measuring stages of change, perceived barriers and self efficacy for physical activity in Saudi Arabia. Asian Pac J Cancer Prev APJCP. 2013;14(2):1009-16. https://doi.org/10. 7314/apjcp.2013.14.2.1009.

19. Albarrak AI, Mohammed R, Zakaria N, Alyousef LM, Almefgai NB, Alqahtani HD, et al. The impact of obesity related websites on decision making among students in Saudi Arabia. Saudi Pharm J. 2016;24(5):605-10. https://doi.org/10.1016/j.jsps.2015.03.016.
20. Al-Isa AN, Campbell J, Desapriya E, Wijesinghe N. Social and health factors associated with physical activity among Kuwaiti college students. J Obes. 2011;2011:1-6. https://doi.org/10.1155/ 2011/512363.

21. Al-Shahrani AM, Al-Khaldi YM. Experience of the health promotion clinics in Aseer region, Saudi Arabia. J Fam Community Med 2011;18(3):130-134. doi:https://doi.org/10.4103/2230-8229. 90012.

22. Al Rashdan I, Al NY. Prevalence of overweight, obesity, and metabolic syndrome among adult Kuwaitis: results from communitybased national survey. Angiology. 2010;61(1):42-8. https://doi. org/10.1177/0003319709333226.

23. Al Riyami A, Al Hadabi S, Abd El Aty MA, Al Kharusi H, Morsi M, Jaju S. Nutrition knowledge, beliefs and dietary habits among elderly people in Nizwa, Oman: implications for policy. East Mediterr Health J. 2010;16(8):859-67.

24. Musaiger AO, Al-Mannai M. Role of obesity and media in body weight concern among female university students in Kuwait. Eat Behav. 2013;14(2):229-32. https://doi.org/10.1016/j.eatbeh.2012. 12.004 .

25. Al Dokhi L, Habib SS. Assessment of gender differences in body composition and physical fitness scoring in Saudi adults by bioelectrical impedance analysis. Acta Clin Croat. 2013;52(2):189-94.

26. Al Zenki S, Al Omirah H, Al Hooti S, et al. High prevalence of metabolic syndrome among Kuwaiti adults-a wake-up call for public health intervention. Int J Environ Res Public Health. 2012;9(5): 1984-96. https://doi.org/10.3390/ijerph9051984.

27. Hajat $\mathrm{C}$, Harrison $\mathrm{O}$, Shather Z. A profile and approach to chronic disease in Abu Dhabi. Glob Health. 2012;8(1):18. https://doi.org/ 10.1186/1744-8603-8-18.

28. Koehring M. Confronting obesity in the Middle East: cultural, social and policy challenges, vol. 19. Middle East: Economist Intelligence Unit (EIU); 2016. https://eiuperspectives.economist. com/sites/default/files/ConfrontingobesityintheMiddleEast 0.pdf. Accessed December 11, 2019

29. on behalf of the ProActive study group, Golubic R, Wijndaele K, et al. Physical activity, sedentary time and gain in overall and central body fat: 7-year follow-up of the ProActive trial cohort. Int J Obes. 2015;39(1):142-8. https://doi.org/10.1038/ijo.2014.66.

30. Sharara E, Akik C, Ghattas H, Makhlouf OC. Physical inactivity, gender and culture in Arab countries: a systematic assessment of the literature. BMC Public Health. 2018;18(1):639. https://doi.org/10. 1186/s12889-018-5472-Z.

31. AlAteeq MA, AlArawi SM. Healthy lifestyle among primary health care professionals. Saudi Med J. 2014;35(5):488-94.

32. Amin TT, Suleman W, Ali A, Gamal A, Al WA. Pattern, prevalence, and perceived personal barriers toward physical activity among adult Saudis in Al-Hassa, KSA. J Phys Act Health. 2011;8(6):775-84. https://doi.org/10.1123/jpah.8.6.775.

33. Musaiger AO, Awadhalla MS, Al-Mannai M, AlSawad M, Asokan GV. Dietary habits and sedentary behaviors among health science university students in Bahrain. Int J Adolesc Med Health. 2015;29(2). https://doi.org/10.1515/ijamh-2015-0038.

34. Mabry RM, Morsi M, Al-Lawati JA, Owen N. Descriptive epidemiology of physical activity among Omani adults: the Oman World Health Survey, 2008. East Mediterr Health J. 2016;22(2):103-15. https://doi.org/10.26719/2016.22.2.103.

35. Awadalla NJ, Aboelyazed AE, Hassanein MA, et al. Assessment of physical inactivity and perceived barriers to physical activity among health college students, south-western Saudi Arabia. East Mediterr Health J. 2014;20(10):596-604.

36. Sayegh S, Van Der Walt M, Al-Kuwari MG. One-year assessment of physical activity level in adult Qatari females: a pedometer-based longitudinal study. Int J Women's Health. 2016;8:287-93. https:// doi.org/10.2147/IJWH.S99943. 
37. Allafi AR, Waslien C. Association of unhealthy exercise patterns with overweight and obesity in Kuwaiti adults. Iran J Public Health. 2014;43(11):1497-502.

38. Almajwal AM. Correlations of physical activity, body mass index, shift duty, and selected eating habits among nurses in Riyadh, Saudi Arabia. Ecol Food Nutr. 2015;54(4):397-417. https://doi.org/10. 1080/03670244.2015.1004400.

39. Khalaf A, Ekblom Ö, Kowalski J, Berggren V, Westergren A, A1Hazzaa H. Female University students' physical activity levels and associated factors - a cross-sectional study in southwestern Saudi Arabia. Int J Environ Res Public Health. 2013;10(8):3502-17. https://doi.org/10.3390/ijerph10083502.

40. Al-Rafaee SA, Al-Hazzaa HM. Physical activity profile of adult males in Riyadh City. Saudi Med J. 2001;22(9):784-9.

41. Benjamin K, Donnelly T. Barriers and facilitators influencing the physical activity of Arabic adults: a literature review. Avicenna. 2013;2013:8. https://doi.org/10.5339/avi.2013.8.

42. Kahan D. Arab American college students' physical activity and body composition: reconciling Middle East-West differences using the socioecological model. Res Q Exerc Sport. 2011;82(1):118-28. https://doi.org/10.1080/02701367.2011.10599728.

43. Ali HI, Baynouna LM, Bernsen RM. Barriers and facilitators of weight management: perspectives of Arab women at risk for type 2 diabetes. Health Soc Care Commun. 2010;18(2):219-28. https:// doi.org/10.1111/j.1365-2524.2009.00896.x.

44. Rahim HFA, Sibai A, Khader Y, Hwalla N, Fadhil I, Alsiyabi H, et al. Non-communicable diseases in the Arab world. Lancet. 2014;383(9914):356-67.

45. Swinburn BA, Sacks G, Hall KD, McPherson K, Finegood DT, Moodie ML, et al. The global obesity pandemic: shaped by global drivers and local environments. Lancet. 2011;378(9793):804-14.

46. Al-Mannai A, Dickerson JW, Morgan JB, Khalfan H. Obesity in Bahraini adults. J R Soc Health. 1996;116(1):30-2, 37-40. https:// doi.org/10.1177/146642409611600108.

47. Al-Otaibi HH. The pattern of fruit and vegetable consumption among Saudi university students. Glob J Health Sci. 2013;6(2): 155-62. https://doi.org/10.5539/gihs.v6n2p155.

48. Al-Rethaiaa AS, Fahmy A-EA, Al-Shwaiyat NM. Obesity and eating habits among college students in Saudi Arabia: a cross sectional study. Nutr J. 2010;9:39. https://doi.org/10.1186/1475-2891-9-39.

49. Mabry RM, Winkler EAH, Reeves MM, Eakin EG, Owen N. Correlates of Omani adults' physical inactivity and sitting time. Public Health Nutr. 2013;16(1):65-72. https://doi.org/10.1017/ S1368980012002844

50. Zaghloul S, Waslien C, Al Somaie M, Prakash P. Low adherence of Kuwaiti adults to fruit and vegetable dietary guidelines. East Mediterr Health J. 2012;18(5):461-7. https://doi.org/10.26719/ 2012.18.5.461

51. El Hamid Hussein RA. Can knowledge alone predict vegetable and fruit consumption among adolescents? A transtheoretical model perspective. J Egypt Public Health Assoc. 2011;86(5-6):95-103. https://doi.org/10.1097/01.EPX.0000407136.38812.55.

52. Mandil AM, Alfurayh NA, Aljebreen MA, Aldukhi SA. Physical activity and major non-communicable diseases among physicians in Central Saudi Arabia. Saudi Med J. 2016;37(11):1243-50. https://doi.org/10.15537/smj.2016.11.16268.

53. Musaiger AO. Consumption, health attitudes and perception toward fast food among Arab consumers in Kuwait: gender differences. Glob J Health Sci. 2014;6(6):136-43. https://doi.org/10.5539/ gjhs.v6n6p136.

54. Almajwal AM. Stress, shift duty, and eating behavior among nurses in Central Saudi Arabia. Saudi Med J. 2016;37(2):191-8. https:// doi.org/10.15537/smj.2016.2.13060.

55. El Hamid Hussein RA. Socioeconomic status and dietary habits as predictors of home breakfast skipping in young women. J Egypt
Public Health Assoc. 2014;89(2):100-4. https://doi.org/10.1097/ 01.EPX.0000452288.49308.40.

56. Geiker NRW, Astrup A, Hjorth MF, Sjödin A, Pijls L, Markus CR. Does stress influence sleep patterns, food intake, weight gain, abdominal obesity and weight loss interventions and vice versa? Obes Rev. 2018;19(1):81-97. https://doi.org/10.1111/obr.12603.

57. Fatima Y, Doi SAR, Mamun AA. Longitudinal impact of sleep on overweight and obesity in children and adolescents: a systematic review and bias-adjusted meta-analysis. Obes Rev. 2015;16(2): 137-49. https://doi.org/10.1111/obr.12245.

58. Alodhayani AA, Alshaikh OM, Ghomraoui FA, AlShaibani TJ, Algadheeb AS, Bendahmash AW, et al. Correlation between obesity and sleep disturbance in Saudi medical students. J Phys Ther Sci. 2017;29(2):181-6. https://doi.org/10.1589/jpts.29.181.

59. Azzeh FS, Bukhari HM, Header EA, Ghabashi MA, Al-Mashi SS, Noorwali NM. Trends in overweight or obesity and other anthropometric indices in adults aged 18-60 years in western Saudi Arabia. Ann Saudi Med. 2017;37(2):106-13. https://doi.org/10. 5144/0256-4947.2017.106.

60. Borgan SM, Jassim GA, Marhoon ZA, Ibrahim MH. The lifestyle habits and wellbeing of physicians in Bahrain: a cross-sectional study. BMC Public Health. 2015;15(1):655. https://doi.org/10. 1186/s12889-015-1969-x.

61. Bronfenbrenner U. The ecology of human development: Harvard University Press; 1979.

62. Yee SL, Williams-Piehota P, Sorensen A, Roussel A, Hersey J, Hamre R. The nutrition and physical activity program to prevent obesity and other chronic diseases: monitoring progress in funded states. Prev Chronic Dis. 2006;3(1):A23.

63. Musaiger AO, Al Hazzaa HM, Al-Qahtani A, et al. Strategy to combat obesity and to promote physical activity in Arab countries. Diabetes Metab Syndr Obes. 2011;4:89-97. https://doi.org/10. 2147/DMSO.S17322.

64. Alsukait R, Wilde P, Bleich S, Singh G, Folta S. Impact of Saudi Arabia's sugary drink tax on prices and purchases (P10-066-19). Curr Dev Nutr. 2019;3. https://doi.org/10.1093/cdn/nzz034.p10066-19.

65. Hajat $\mathrm{C}$, Harrison $\mathrm{O}, \mathrm{Al} \mathrm{SZ}$. Weqaya: a population-wide cardiovascular screening program in Abu Dhabi, United Arab Emirates. Am J Public Health. 2012;102(5):909-14. https://doi.org/10.2105/AJPH. 2011.300290.

66. Abdulle A, Alnaeemi A, Aljunaibi A, al Ali A, al Saedi K, al Zaabi E, et al. The UAE healthy future study: a pilot for a prospective cohort study of 20,000 United Arab Emirates nationals. BMC Public Health. 2018;18:101. https://doi.org/10.1186/s12889-0175012-2.

67. Omar O, Arora T. qatar-obesity-reduction-study-qors-report-on-apilot-schoolbased-nutrition-education-campaign-in-qatar Endoscopic Treatments for Obesity View project Obstructive Sleep Apnoea View project Sopna Choudhury Weill Cornell Medicine in Qatar Qatar Obesity Reduction Study (QORS): Report on a Pilot School-based Nutrition Education Campaign in Qatar. 2018. doi: https://doi.org/10.21767/2572-5394.65

68. Al-Alahmed ZA, Al-Omary SA, Alharbi SM. RASHAKA Program: a collaborative initiative between Ministry of Health and Ministry of Education to control childhood obesity in Saudi Arabia. Saudi J Obes. 2017;5(1):22. https://doi.org/10.4103/SJO. SJO 5 _ 17.

69. Abusnana S, Fargaly M, Alfardan SH, al Hammadi FH, Bashier A, Kaddaha $\mathrm{G}$, et al. Clinical practice recommendations for the management of obesity in the United Arab Emirates. Obes Facts. 2018;11(5):413-28. https://doi.org/10.1159/000491796.

70. Donnelly TT, Bint Mohammed Al-Thani AA, Benjamin K, et al. Arab female and male perceptions of factors facilitating and inhibiting their physical activity: findings from a qualitative study 
in the Middle East. PLoS One. 2018. https://doi.org/10.1371/ journal.pone.0199336.

71. Alnasser A, Kyle J, Aloumi N, Al-Khalifa A, Marais D. The Twazon Arabic weight loss app: app-based intervention for Saudi women with obesity. JMIR MHealth UHealth. 2019;7(5):e10923. https://doi.org/10.2196/10923.

72. Alghamdi RQ. A randomized controlled trial of a 12-week intensive lifestyle intervention program at a primary care obesity clinic for adults in western Saudi Arabia. Saudi Med J. 2017;38(8):83745. https://doi.org/10.15537/smj.2017.8.20553.

73. Armitage CJ, Alganem S, Norman P. Randomized controlled trial of a volitional help sheet to encourage weight loss in the Middle East. Prev Sci. 2017;18(8):976-83. https://doi.org/10.1007/s11121017-0807-z.

74. Armitage CJ, Norman P, Noor M, Alganem S, Arden MA. Evidence that a very brief psychological intervention boosts weight loss in a weight loss program. Behav Ther. 2014;45(5):700-7. https://doi.org/10.1016/j.beth.2014.04.001.
75. Alqahtani A, Alamri H, Elahmedi M, Mohammed R. Laparoscopic sleeve gastrectomy in adult and pediatric obese patients: a comparative study. Surg Endosc. 2012;26(11):3094-100. https://doi.org/ 10.1007/s00464-012-2345-x.

76. Himpens J, Ramos A, Welbourn R, Dixon J, Kinsman R, Walton P. IFSO Global Registry Report 2018. :84.

77. Maps LUKS map: G. Kuwait publishes 1st National Bariatric Registry Report. Bariatric News https://bariatricnews.net/?q= news/113465/kuwait-publishes-1st-national-bariatric-registryreport. Accessed December 16, 2019.

78. Batterjee Medical College, Mahfooz S. Outcome of bariatric surgery in Saudi Arabia: a systematic review. Int J Adv Res. 2018;6(1): 1275-81. https://doi.org/10.21474/IJAR01/6347.

Publisher's Note Springer Nature remains neutral with regard to jurisdictional claims in published maps and institutional affiliations. 